\title{
Additive Effect of Stress and Drug Cues on Reinstatement of Ethanol Seeking: Exacerbation by History of Dependence and Role of Concurrent Activation of Corticotropin-Releasing Factor and Opioid Mechanisms
}

\author{
Xiu Liu and Friedbert Weiss \\ Department of Neuropharmacology, The Scripps Research Institute, La Jolla, California 92037
}

\begin{abstract}
Stress and exposure to drug-related environmental stimuli have been implicated as critical factors in relapse to drug use. What has received little attention, however, is the significance of interactions between these factors for motivating drug-seeking behavior. To address this issue, a reinstatement model of relapse was used. Footshock stress and response-contingent presentation of an ethanol-associated light cue, acting as a conditioned stimulus (CS), effectively reinstated extinguished responding at a previously active, drug-paired lever in male Wistar rats. When response-contingent availability of the ethanol CS was preceded by footshock, additive effects of these stimuli on responding were observed. Both the individual and interactive effects of footshock and the CS were significantly greater in previously ethanol-dependent than in nondependent
\end{abstract}

Drug and alcohol addiction are chronically relapsing disorders. Much effort has therefore been directed at understanding the environmental and neural basis of relapse. Major factors implicated in the resumption of drinking or drug use include subjective reactions provoked by stressful events (Brown et al., 1995; Sinha et al., 2000) and by environmental stimuli that have become conditioned to the pharmacological actions of drugs or alcohol (Cooney et al., 1997; O’Brien et al., 1998; Sinha et al., 2000). The significance of stress and conditioning factors for the addictive potential of drugs of abuse is also well documented in the animal literature. Footshock stress consistently elicits reinstatement of drug-seeking (for review, see Shaham et al., 2000) and ethanolseeking behavior (Le et al., 1998; Martin-Fardon et al., 2000) in drug-free animals. Similarly, exposure to environmental stimuli conditioned to drug presentation or availability reliably induces recovery of responses previously reinforced by drug or alcohol delivery (Meil and See, 1996; Ciccocioppo et al., 2001).

Although there is substantial evidence for a role of drugrelated stimuli and stress in reinstatement and relapse, the significance of interactions between these variables for drug-seeking behavior has received little experimental attention. The resump-

\footnotetext{
Received May 9, 2002; revised June 27, 2002; accepted July 10, 2002.

This is publication 12720-NP from The Scripps Research Institute. This work was supported by National Institutes of Health/National Institute on Alcohol Abuse and Alcoholism Grant AA10531 (F.W.). We thank Mike Arends for assistance with the preparation of this manuscript.

Correspondence should be addressed to Friedbert Weiss, Department of Neuropharmacology, CVN-15, The Scripps Research Institute, 10550 North Torrey Pines Road, La Jolla, CA 92037. E-mail: bweiss@scripps.edu.

Copyright (C) 2002 Society for Neuroscience $0270-6474 / 02 / 227856-06 \$ 15.00 / 0$
}

rats. Responding induced by the ethanol CS was selectively reversed by the nonselective opiate antagonist naltrexone, whereas the effects of footshock were selectively reversed by the corticotropin-releasing factor (CRF) antagonist D-Phe$\mathrm{CRF}_{12-41}$. However, both agents only partially reversed the enhanced drug-seeking response produced by the interactive effects of stress and the ethanol CS; full reversal required coadministration of $\mathrm{D}-\mathrm{Phe}-\mathrm{CRF}$ and naltrexone. The results document that stress and drug-related environmental stimuli interact to augment the resumption of drug seeking after extinction and suggest that this effect results from concurrent activation of opioid and CRF transmission.

Key words: ethanol; dependence; footshock; conditioned stimulus; naltrexone; $D-P h e-C R F$ tion of addictive behavior during abstinence often is associated with the presence of multiple risk factors (Cooney et al., 1997). Thus, it is possible that different motivationally relevant conditions such as drug cues and stress may interact to increase the likelihood of resumption or intensity of drug-seeking behavior. To test this hypothesis, a reinstatement model of relapse was used, comparing the individual with the interactive effects of brief footshock stress and presentation of an ethanol-associated conditioned stimulus (CS) on the recovery of responding at a previously active, ethanol-paired lever. Additionally, to examine the relevance of drug history as a factor in the resumption of alcoholseeking behavior under these conditions, both ethanol nondependent rats and rats made dependent on ethanol but withdrawn 3 weeks before testing were studied. Finally, these experiments sought to determine whether drug seeking induced by the interactive effects of stress and alcohol cues can be dissociated neuropharmacologically or recruits shared neural mechanisms. For this purpose, the sensitivity of the interactive effects of footshock and the ethanol CS to reversal by the corticotropin-releasing factor (CRF) antagonist D-Phe-CRF versus the nonselective opiate antagonist naltrexone [agents known to block the respective behavioral effects of footshock (Le et al., 2000) and alcohol cues (Ciccocioppo et al., 2002)] was examined.

\section{MATERIALS AND METHODS}

Animals. Male Wistar rats (Charles River, Raleigh, NC) weighing 450$600 \mathrm{gm}$ at the time of testing were housed three per cage on a $12 \mathrm{hr}$ light/dark cycle. Food and water were available ad libitum in the home cage. Training and testing were conducted during the dark phase at the same time each day. All experimental procedures were carried out in 
accordance with the National Institutes of Health Guide for the Care and Use of Laboratory Animals.

Ethanol self-administration and cue conditioning. All procedures were conducted in operant conditioning chambers (Coulborn Instruments, Allentown, PA) enclosed in sound-attenuating cubicles. The chambers were equipped with two retractable levers located on either side of a drinking reservoir positioned in the center of the front panel of the chamber. Rats were trained to orally self-administer ethanol in daily 30 min sessions using a sweet solution fading procedure (for details, see Weiss et al., 1993). Briefly, rats were placed on a restriction schedule limiting water availability to $2 \mathrm{hr} / \mathrm{d}$ for $3 \mathrm{~d}$. During this time, selfadministration training sessions were initiated by extension of the right lever, and each lever response was reinforced by $0.1 \mathrm{ml}$ of a $0.2 \%(\mathrm{w} / \mathrm{v})$ saccharin solution. Water then was made available again ad libitum in the home cage and, on day four, ethanol self-administration was initiated by adding $5 \%(\mathrm{w} / \mathrm{v})$ ethanol to the saccharin solution. Over the next 3 weeks, ethanol concentrations were increased gradually to $10 \%(\mathrm{w} / \mathrm{v})$ while saccharin was slowly eliminated. During this time, the response requirement was raised to a fixed ratio of 3 , and each reinforced response was paired with illumination of a white cue light $(24 \mathrm{~W})$ above the lever for $0.5 \mathrm{sec}$. In addition, a second but inactive lever was introduced. Responses at this lever were recorded as a measure of nonspecific behavioral activation but had no programmed consequences. Selfadministration of $10 \%$ ethanol under these contingencies continued in daily sessions for 6 weeks.

Dependence induction. After completion of self-administration training, rats were divided into two groups. One group $(n=21)$ was subjected to $12 \mathrm{~d}$ of dependence induction using ethanol vapor inhalation chambers in which rats were continuously exposed to an air and ethanol $(0.25 \%)$ mixture sustaining blood alcohol levels (BALs) of 180-220 mg\% (Macey et al., 1996). The remaining rats $(n=21)$ also were housed in vapor chambers but remained on non-ethanol-containing air. Beginning with day 10 of this procedure, vapor exposure was alternated with ethanol availability via operant self-administration to ascertain that ethanol continues to act as a reinforcer in the dependent state. Rats were transferred to the self-administration chambers and given access to ethanol for $12 \mathrm{hr}$. Food and water (from a drinking bottle) were available ad libitum during this time. Rats then were returned to ethanol vapor for the remaining $12 \mathrm{hr}$ of the day. This cycle of ethanol self-administration followed by ethanol vapor exposure was repeated three times. Nondependent rats (i.e., rats maintained on control air) received responsecontingent access to ethanol according to the same protocol. Ethanolreinforced responses were not paired with presentation of the cue light in either group. After the final cycle of vapor exposure on day 12, all rats were returned to the vivarium.

Extinction of ethanol-reinforced responding. Seven to ten days after removal from the vapor chambers, ethanol-reinforced responding was extinguished in daily $30 \mathrm{~min}$ sessions. Before each extinction session, all rats were placed in footshock chambers (i.e., operant conditioning chambers distinct from those used for ethanol self-administration and reinstatement tests) for $10 \mathrm{~min}$ without receiving shock to habituate the animals to the procedures on the test day. Animals then were transferred to the self-administration chambers where responses at the previously ethanol-paired lever activated the syringe pump but did not deliver ethanol and had no other programmed consequences. Daily sessions continued until all rats reached an extinction criterion of less than or equal to six responses per session for 3 consecutive days.

Reinstatement tests. One day after the final extinction session, both non-dependent and post-dependent rats were divided randomly into three groups and tested for recovery of responding at the previously active lever under one of three conditions: during response-contingent presentation of the ethanol CS alone (EtOH CS), after exposure to footshock alone (STRESS), and during response-contingent presentation of the ethanol CS after exposure to footshock (STRESS + EtOH CS). All rats first were placed into the footshock chambers. Rats assigned to the STRESS and STRESS + EtOH CS conditions were exposed to 10 min of variable intermittent footshock $(0.5 \mathrm{~mA} ; 0.5 \mathrm{sec}$ duration; mean intershock interval, $40 \mathrm{sec}$; range, $10-70 \mathrm{sec}$ ) delivered through a scrambler to the stainless steel grid floor of the chambers. Rats assigned to the EtOH CS condition remained in the chambers for $10 \mathrm{~min}$ without receiving footshock. Rats then were moved to the self-administration chambers where 30 min reinstatement tests began by extension of both levers. Rats in the EtOH CS and STRESS + EtOH CS conditions were tested with response-contingent presentation of the ethanol CS. The ethanol CS was absent in rats tested under STRESS only conditions. In all groups, responses at the previously ethanol-paired lever activated the syringe pump but did not result in delivery of ethanol.

Pharmacological tests. These experiments were conducted in a separate group of rats. Because non-dependent rats did not show reliable responding in all reinstatement conditions, only post-dependent rats $(n=$ 108) were studied. All procedures were identical to those described above. Before the extinction phase, rats designated for testing with D-Phe-CRF ${ }_{12-41}$ (see below) were implanted stereotaxically (Kopf Instruments, Tujunga, CA) under halothane $(1.0-1.5 \%)$ anesthesia with unilateral guide cannulas (23 gauge) aimed at the right lateral ventricle (anterior, -0.6; medial, \pm 2.0 ; ventral, 3.2; Paxinos and Watson, 1998). Intracerebroventricular injections were administered via an injector that extended $1 \mathrm{~mm}$ beyond the guide cannula. At the end of the experiment, rats were injected intracerebroventricularly with $2 \mu \mathrm{l}$ of methylene blue, and cannula placements were verified histologically. Rats were given $7 \mathrm{~d}$ of recovery before the start of extinction sessions.

Thirty minutes before reinstatement tests, rats were treated with the $\mathrm{CRF}$ antagonist D-Phe-CRF ${ }_{12-41}(0,1,10 \mu \mathrm{g}$, i.c.v. $)$ or the nonselective opiate antagonist naltrexone $(0.0,0.25,1.0 \mathrm{mg} / \mathrm{kg}$, s.c.). D-Phe-CRF (kindly provided by the Clayton Foundation Laboratories for Peptide Biology; The Salk Institute, La Jolla, CA) was dissolved in $0.9 \%$ saline and administered in a volume of $5 \mu \mathrm{l}$. Naltrexone (Sigma, St. Louis, MO) was dissolved in $0.9 \%$ saline. Separate groups of rats were used for each drug, dose, and reinstatement test condition ( $n=6$ per group). An additional group was tested after coadministration of naltrexone (1.0 $\mathrm{mg} / \mathrm{kg})$ and D-Phe-CRF $(10 \mu \mathrm{g})(n=6)$ or their vehicle solutions $(n=$ $6)$. This group was tested for the effects of STRESS + EtOH CS only.

\section{RESULTS}

The mean $( \pm$ SEM) number of responses across the last three sessions of self-administration training was $30.9 \pm 2.5$, corresponding to a mean $( \pm S E M)$ ethanol intake of $0.65 \pm 0.05 \mathrm{gm} / \mathrm{kg}$. Rats required $19 \pm 2$ sessions to reach the extinction criterion. During the vapor inhalation period, mean ( \pm SEM) BALs, determined from $50 \mu \mathrm{l}$ of tail blood samples (collected every other day in all rats) and analyzed by an enzymatic oxygen rate analyzer (GM7 Microstat; Analox Instruments, Lunenburg, MA), were $189.6 \pm 16.3 \mathrm{mg} \%$ in dependent (i.e., ethanol vapor-exposed) rats. No significant BALs were detected in nondependent rats maintained on control air. Ethanol supported operant responding in dependent rats during the last $3 \mathrm{~d}$ of dependence induction. Moreover, ethanol intake during the three $12 \mathrm{hr}$ sessions was significantly greater in dependent than nondependent rats with mean \pm SEM responses per day of $544.1 \pm 58.4$ versus $192.3 \pm$ $27.5\left(F_{(1,40)}=29.71 ; p<0.0001\right)$, corresponding to a mean \pm SEM daily ethanol intake (in grams per kilogram) of $9.58 \pm 1.1$ versus $3.48 \pm 0.5\left(F_{(1,40)}=27.40 ; p<0.0001\right)$. Ethanol vaporexposed rats showed moderate signs of withdrawal (measured using a 6-point rating scale as in Macey et al., 1996) 8-12 hr after removal from ethanol vapor with a mean ( \pm SEM) withdrawal score of $4.8 \pm 0.3$. Withdrawal signs in non-dependent controls were negligible $(0.9 \pm 0.2)$.

\section{Extinction}

All rats reached the extinction criterion within $19 \pm 2 \mathrm{~d}$. No significant differences were observed in the time to extinction between non-dependent and post-dependent rats or among subgroups of post-dependent rats designated for testing under different reinstatement conditions.

\section{Reinstatement}

In nondependent rats, neither footshock nor response-contingent availability of the EtOH CS increased responding over extinction levels. However, significant recovery of responding was observed when availability of the EtOH CS was preceded by footshock (Fig. 1). Differences between the STRESS + EtOH CS versus STRESS $(p<0.05)$ and EtOH CS $(p<0.05)$ conditions were 


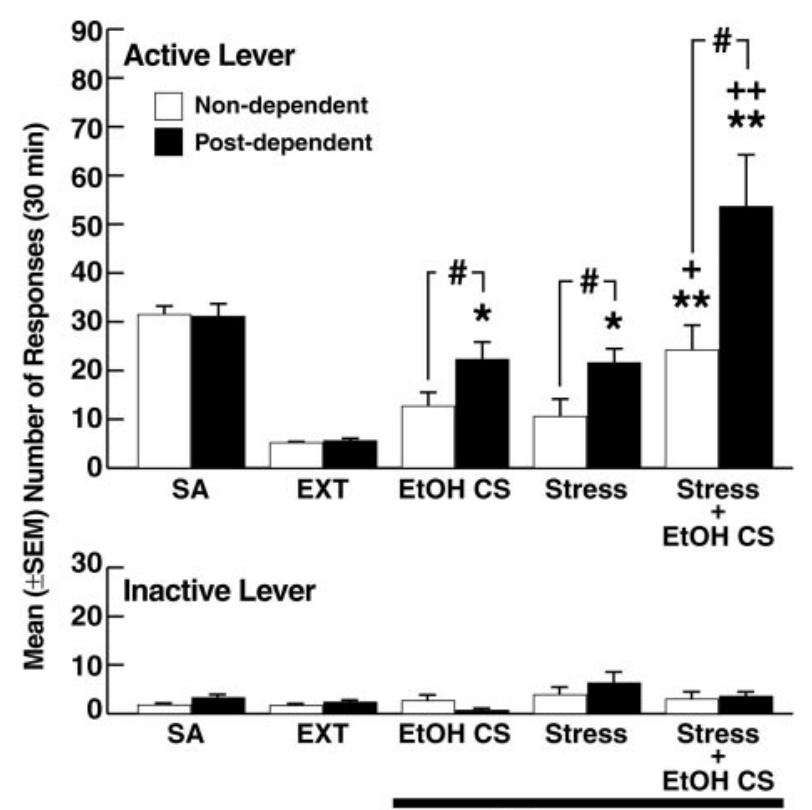

Reinstatement

Figure 1. Responses at a previously active and inactive lever in nondependent and post-dependent rats. $S A$, Ethanol-reinforced responses at the end of self-administration training; $E X T$, responses during the final three extinction sessions; Reinstatement, responses after intermittent footshock (Stress), during response-contingent presentation of an ethanolassociated conditioned stimulus (EtOH CS), and response-contingent presentation of the EtOH CS after footshock (Stress + EtOH CS). ${ }^{*} p<$ $0.05 ; * *<0.01$ different from extinction; $+p<0.05 ;++p<0.01$ different from Stress and EtOH CS; \#p $<0.05$ differences between non-dependent and post-dependent rats.

confirmed by statistical analysis (Newman-Keuls after one-way ANOVA: $\left.F_{(2,18)}=6.29 ; p<0.01\right)$.

In previously dependent rats, both footshock and the EtOH CS produced significant recovery of responding, and this effect was substantially enhanced in the STRESS + EtOH CS condition (Fig. 1). Statistical analysis confirmed increases in the STRESS $(p<0.05)$, EtOH CS $(p<0.05)$, and STRESS + EtOH CS $(p<$ $0.01)$ conditions over extinction responses (simple effects after mixed-factorial ANOVA: $\left.F_{(2,18)}=7.14 ; p<0.01\right)$ as well as significant differences between the STRESS + EtOH CS versus both the STRESS $(p<0.01)$ and EtOH CS $(p<0.01)$ groups (Newman-Keuls after one-way ANOVA: $F_{(2,18)}=7.83 ; p<$ $0.01)$. ANOVA also revealed significant overall differences in responses between post-dependent and non-dependent rats, reflected by a main effect of dependence status $\left(F_{(1,36)}=16.01 ; p<\right.$ $0.001)$ and an interaction between dependence status and reinstatement condition $\left(F_{(1,36)}=12.92 ; p=0.001\right)$. Simple effects confirmed that post-dependent rats differed significantly $(p<$ 0.05 ) from non-dependent rats in each reinstatement condition.

As illustrated by the cumulative responses (Fig. 2), rats tested with either footshock or the EtOH CS alone ceased responding within 15-20 min of session onset. In contrast, responding in the STRESS + EtOH CS condition was sustained throughout the sessions in both post-dependent and non-dependent rats. In the post-dependent group, this effect was confirmed by a significant interaction between the response profiles in the STRESS + EtOH CS versus STRESS and EtOH CS conditions $\left(F_{(10,90)}=\right.$ 4.61; $p<0.0001)$.
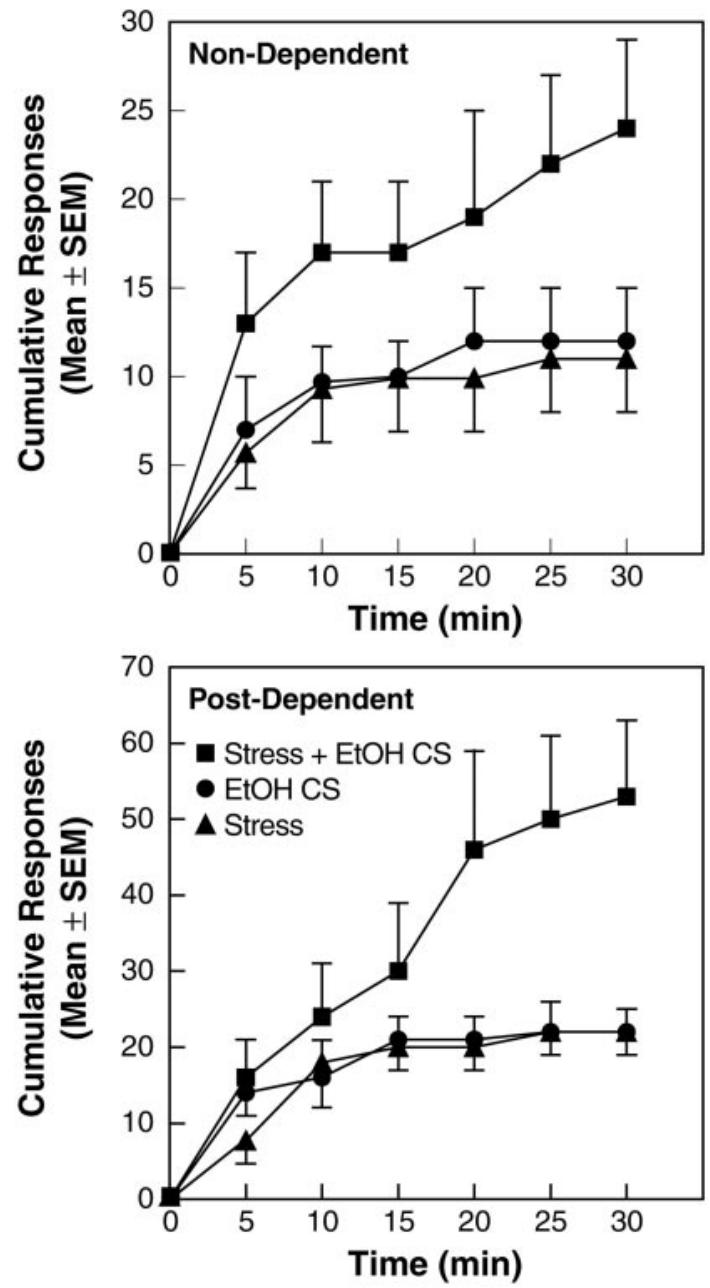

Figure 2. Cumulative responses in the Stress, EtOH CS, and Stress + EtOH CS conditions. [Note different ordinate scales for non-dependent (top) and post-dependent (bottom).]

\section{Effects of D-Phe-CRF and naltrexone}

In vehicle-treated rats, footshock and the EtOH CS elicited significant recovery of responding similar to that in the corresponding post-dependent groups of the first experiment. Also, responding in the STRESS + EtOH CS condition was approximately twofold greater than in the footshock or the EtOH CS conditions, replicating the central finding of experiment 1 . Responses at the inactive lever were negligible and remained unaltered by any of the drug treatments (Fig. 3).

D-Phe-CRF dose-dependently reversed footshock-induced responding with a significant $(p<0.05)$ reduction to extinction levels at the $10 \mu \mathrm{g}$ dose. D-Phe-CRF did not alter the effects of the EtOH CS $\left(F_{(2,15)}=0.10\right.$; NS). The CRF antagonist also dosedependently decreased responding in the STRESS + EtOH CS group with significant effects $(p<0.05)$ at both the 1 and $10 \mu \mathrm{g}$ doses (Newman-Keuls after ANOVA: $F_{(2,15)}=5.07: p<0.05$ ). However, even at the $10 \mu \mathrm{g}$ dose, responding remained significantly $(p<0.05)$ above extinction performance (Fig. 3$)$.

Naltrexone had no effect on stress-induced responses $\left(F_{(2,15)}=\right.$ 0.33 ; NS), but dose-dependently attenuated responding induced by the EtOH CS with a significant $(p<0.05)$ reversal to extinction levels at the $1.0 \mathrm{mg} / \mathrm{kg}$ dose. In addition, naltrexone decreased the response-reinstatement in the STRESS + EtOH CS 


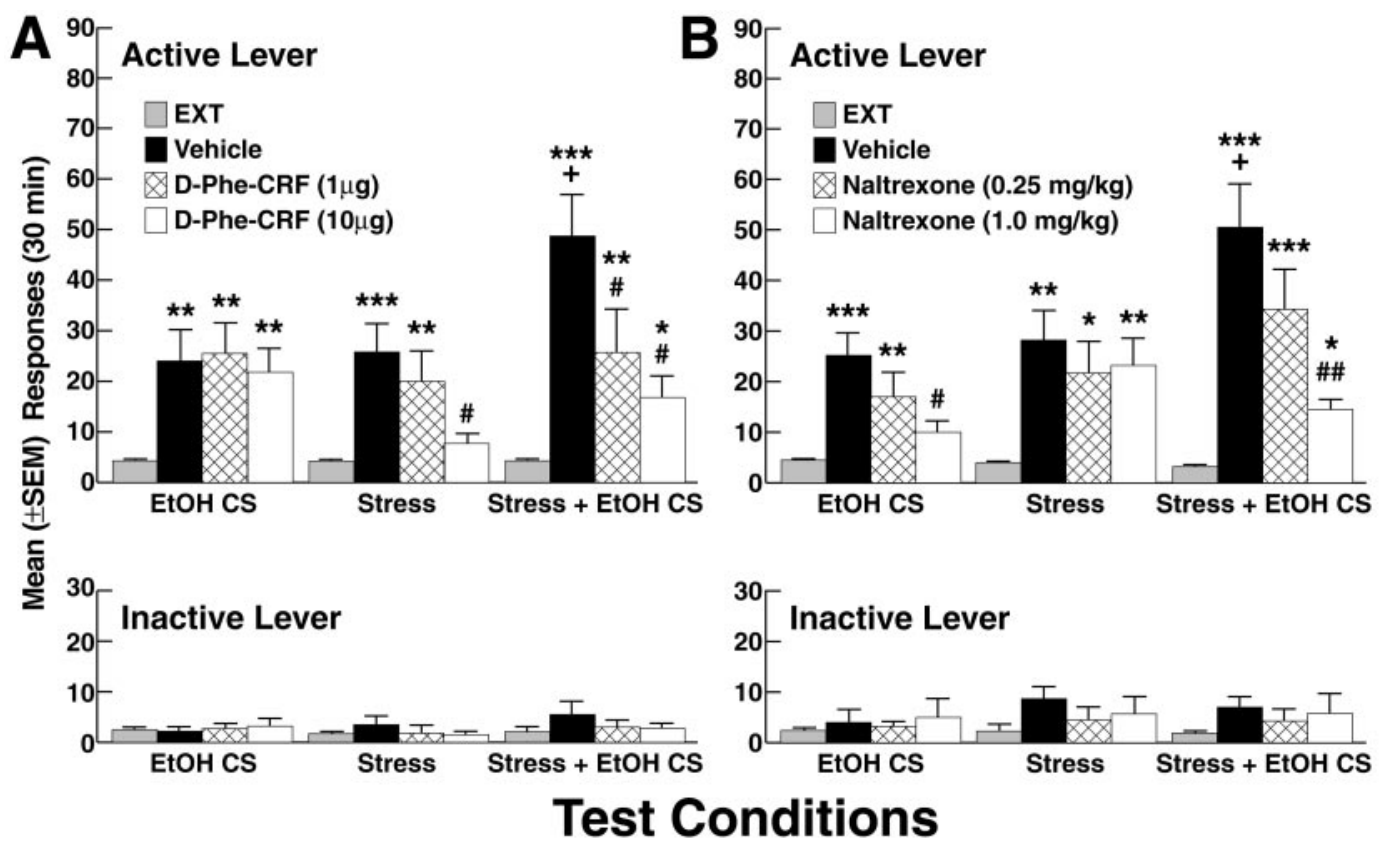

Figure 3. Effects of D-Phe-CRF and naltrexone on reinstatement after extinction $(E X T)$ in the Stress, EtOH CS, and Stress + EtOH CS conditions. D-Phe-CRF antagonized footshock but not EtOH CS-induced responding. Conversely, naltrexone reversed the response-reinstating effects of the EtOH CS but not of footshock. Both D-Phe-CRF and naltrexone partially reversed reinstatement in the Stress + EtOH-CS condition, but responding remained significantly above extinction levels. (Note: For the sake of clarity of the illustration, EXT data have been collapsed across the three groups in each reinstatement condition.) ${ }^{*} p<0.05 ;{ }^{*} p<0.01 ; * * p<0.001$ different from respective extinction performance; $+p<0.05$ different from Stress and EtOH CS vehicle controls; $\# p<0.05 ; \# \# p<0.01$ different from vehicle.

condition with significant effects $(p<0.01)$ at the $1.0 \mathrm{mg} / \mathrm{kg}$ dose (Newman-Keuls after ANOVA: $F_{(2,15)}=6.97 ; p<0.01$ ). Like D-Phe-CRF, the opiate antagonist failed to fully reverse the STRESS + EtOH CS effects because responding remained significantly $(p<0.05)$ above extinction levels at the high $(1.0$ $\mathrm{mg} / \mathrm{kg}$ ) dose (Fig. 3).

Coadministration of D-Phe-CRF $(10 \mu \mathrm{g})$ and naltrexone (1.0 $\mathrm{mg} / \mathrm{kg}$ ) at doses that were effective for the respective individual effects of STRESS and the EtOH CS produced a full reversal of the STRESS + EtOH CS effects to levels indistinguishable $\left(F_{(1,10)}=0.09 ; \mathrm{NS}\right)$ from extinction responses (Fig. 4).

\section{DISCUSSION}

Three major findings were obtained. Footshock and an ethanolassociated conditioned stimulus produced interactive effects substantially augmenting drug-seeking behavior elicited by either of these stimuli alone. Both the individual and interactive effects of footshock and the ethanol cue were further enhanced in rats with a history of ethanol dependence. Finally, the interactive effects of footshock and the ethanol cue were only partially reversible by either a CRF or opiate antagonist, but were fully reversed by concurrent pharmacological blockade of CRF and opioid receptors.

\section{Interactive effects of alcohol cues and stress}

In all tests, responding was confined to the previously active lever, whereas responses at the inactive lever remained indistinguishable from inactive lever responses during the extinction phase. Therefore, the enhancement of the ethanol CS-induced drugseeking response after footshock cannot be attributed to nonspecific motor activation. Instead, this effect is consistent with an augmentation of behavior directed at obtaining the previously available reinforcer (i.e., ethanol). In both non-dependent and post-dependent rats, responses in STRESS + EtOH CS condition were increased approximately twofold over the effects of either footshock or the ethanol CS alone and therefore appear to reflect the additive effects of these stimuli. Interestingly, the individual effects of footshock and the ethanol CS sustained responding only for $\sim 15 \mathrm{~min}$, whereas responding in the STRESS + EtOH CS groups was continuous and interrupted only by termination of the test. Thus, the interactive effects of stress and the drug cue appeared to "energize" drug-seeking, resulting in both quantitative and qualitative differences from the respective individual effects of these stimuli. One may speculate that emotional distress associated with footshock induces a negative affective state in which the incentive salience of ethanol-related stimuli is increased. This interpretation would seem consistent with clinical findings that neither ethanol craving induced by an alcohol cue alone nor negative affect alone predicts relapse in alcoholics, whereas cue-induced craving in the presence of negative affect is a reliable predictor of relapse (Cooney et al., 1997).

\section{Increased cue and stress reactivity in previously dependent rats}

Both the individual and interactive effects of footshock and the EtOH CS were greater in post-dependent than in non-dependent rats, suggesting that the sensitivity to drug cues and stress is increased in rats with a history of ethanol dependence. The results do not provide direct insight into the mechanisms underlying this finding; however, several tentative explanations can be offered. First, in addition to acting as a positive reinforcer, alcohol serves as a negative reinforcer during the development of dependence by alleviating aversive withdrawal symptoms (Roberts et al., 2000). Because the post-dependent groups had received response-contingent access to ethanol at the end of dependence induction and self-administered substantial amounts of 


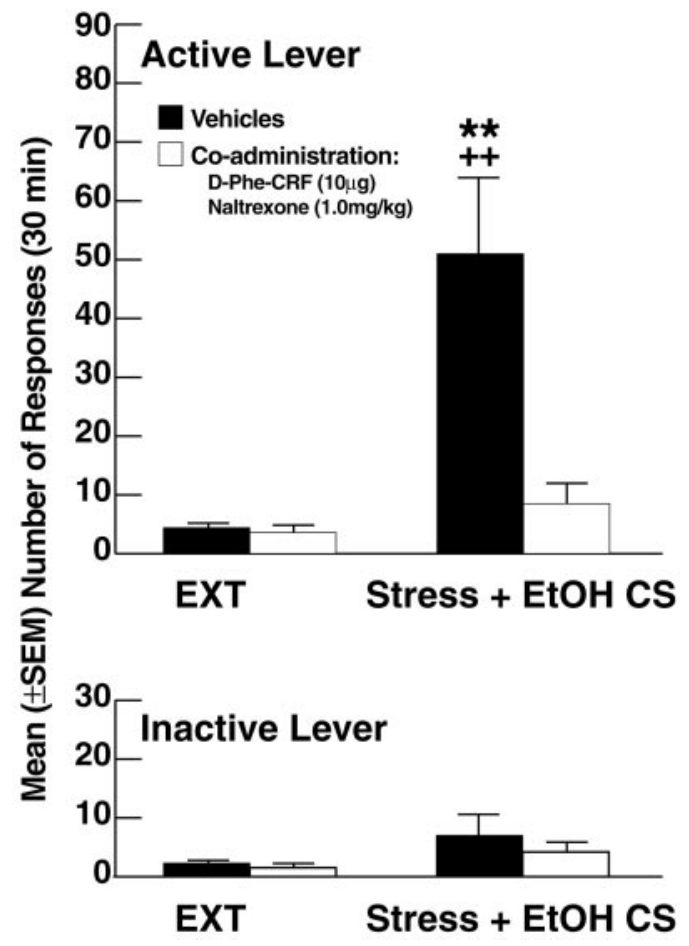

Figure 4. Coadministration of D-Phe-CRF and naltrexone reversed the Stress + EtOH CS interactive effects to levels indistinguishable from extinction $(E X T)$ responses. ${ }^{* *} p<0.01$, different from EXT; $++p<0.01$ different from D-Phe-CRF + naltrexone.

ethanol, the drug may have become associated with the reversal or prevention of withdrawal. This drug-related learning may have increased the salience of ethanol as a reinforcer in these animals (and consequently the motivating effects of the ethanol CS) compared with non-dependent rats for which the drug had served as a positive reinforcer only. Interestingly, clinical studies as well suggest that conditioned responses to drug cues are positively correlated with the degree of alcohol dependence (Glautier and Drummond, 1994; George et al., 2001). Alternatively, or in addition to learning effects, the exacerbation of drug-seeking in postdependent rats may have resulted from neuroadaptive changes in stress-regulatory systems or mechanisms that mediate the incentive-motivational effects of ethanol. Long-lasting dysregulation of neuroendocrine and extrahypothalamic CRF function (Zorrilla et al., 2001) as well as increased sensitivity to stress (G. F. Koob and G. R. Valdez, personal communication) has been documented in previously ethanol-dependent rats. Evidence also exists to suggest that neural mechanisms, including endogenous opioid function, implicated in ethanol-seeking behavior and craving show long-term alterations after chronic ethanol exposure (Topple et al., 1998; Nestby et al., 1999; Lindholm et al., 2000).

Although both footshock and the ethanol CS effectively reinstated responding when tested individually, this effect was limited to previously dependent animals. This finding contrasts with earlier studies that have demonstrated reliable footshock-induced reinstatement (Le et al., 1998, 1999, 2000; Martin-Fardon et al., 2000) or maintenance of conditioned responding by ethanol cues (Wilson et al., 2000) in rats without a history of dependence. These discrepancies are accounted for, however, by methodological differences. Specifically, to reduce the risk of ceiling effects when testing for the interactive effects of dependence status, stress, and the ethanol cue, the reinstatement procedures were designed such that both footshock and the ethanol CS would produce only weak effects of their own. In particular, both the current intensity and duration of footshock exposure were reduced compared with relevant earlier studies. Moreover, footshock was administered outside the test environment and, therefore, presumably was less effective in reinstating ethanol-seeking than has been reported previously in rats subjected to footshock and tested for reinstatement in the same environment (Le et al., 1998, 1999, 2000; Martin-Fardon et al., 2000). Additionally, ethanol reinforcement was conditioned to a simple light cue only rather than a compound stimulus (Wilson et al., 2000), the latter class of stimuli being more effective in reinstating extinguished drug and alcohol-seeking behavior than a single stimulus (See et al., 1999). Nonetheless, although neither footshock nor the ethanol CS were effective in eliciting reinstatement in non-dependent rats, their subthreshold effects were sufficient to produce additive effects, resulting in significant drug-seeking behavior when tested in combination.

\section{Interactive effects of stress and alcohol cues depend on concurrent activation of CRF and opioid receptors}

The effects of footshock and the ethanol CS were differentially sensitive to reversal by D-Phe-CRF and naltrexone. Moreover, both naltrexone and D-Phe-CRF only partially antagonized the interactive effects of footshock and the ethanol CS. Drug-seeking behavior in this condition was completely reversible only by coadministration of both agents. This observation, paired with the high degree of selectivity of D-Phe-CRF and naltrexone for the individual effects of footshock versus the alcohol cue, indicates that footshock and drug cues elicit alcohol-seeking behavior via distinct neural mechanisms involving activation of CRF versus opioid receptors. More importantly, this finding suggests that concurrent activation of these mechanisms in subjects with a history of ethanol dependence leads to an enhanced drug-seeking response. It remains unclear whether the same applies to increased ethanol-seeking behavior associated with the interactive effects of stress and the ethanol cues in rats without a history of ethanol dependence because pharmacological tests were not conducted in non-dependent animals. However, considering ample existing evidence that opioid and CRF antagonists block the respective behavioral effects of footshock (Le et al., 1999, 2000) and alcohol-associated environmental cues (Katner et al., 1999; Ciccocioppo et al., 2002), it seems likely that the enhanced drug-seeking response produced by the interactive effects of footshock and the EtOH CS in non-dependent rats results from concurrent activation of CRF and opioid transmission as well.

Overall, the effects of D-Phe-CRF and naltrexone support existing evidence of a role of CRF receptors in stress-induced reinstatement of drug-seeking behavior (Shaham et al., 2000) and a role of opioid receptors in drug-seeking responses and craving associated with exposure to ethanol cues (Gerrits et al., 1999; Monti et al., 1999; Rohsenow et al., 2000; Ciccocioppo et al., 2002). CRF antagonists consistently reverse footshock-induced reinstatement of cocaine, heroin, and ethanol-seeking behavior, possibly by acting at non-neuroendocrine CRF receptors in the bed nucleus of the stria terminalis and central nucleus of the amygdala (Shaham et al., 2000). The failure of naltrexone to attenuate the effects of footshock parallels similar earlier observations (Le et al., 1999). On the other hand, the antagonism of the ethanol cue effects by naltrexone implicates activation of endogenous opioids in the motivating effects of alcohol-associated environmental stimuli, consistent with previous demonstrations that 
opiate antagonists reverse cue-induced reinstatement (Ciccocioppo et al., 2002) and alcohol craving (Monti et al., 1999; Rohsenow et al., 2000).

In conclusion, the results show that stress and drug-related environmental stimuli interact to facilitate recovery of drugseeking after extinction and that a history of ethanol dependence is associated with an augmented drug-seeking response to alcohol cues and stress as well as their interactive effects. Additionally, the results suggest that the motivating effects of stress and drug cues are mediated by distinct neuropharmacological substrates that, when activated in parallel, exacerbate drug-seeking behavior.

\section{REFERENCES}

Brown SA, Vik PW, Patterson TL, Grant I, Schuckit MA (1995) Stress, vulnerability and adult alcohol relapse. J Studies Alcohol 56:538-545.

Ciccocioppo R, Angeletti S, Weiss F (2001) Long-lasting resistance to extinction of response reinstatement induced by ethanol-related stimuli: role of genetic ethanol preference. Alcohol Clin Exp Res 25:1414-1419.

Ciccocioppo R, Martin-Fardon R, Weiss F (2002) Effect of selective blockade of mu-1 or delta opioid receptors on reinstatement of alcoholseeking behavior by drug-associated stimuli in rats. Neuropsychopharmacology, in press.

Cooney NL, Litt MD, Morse PA, Bauer LO, Gaupp L (1997) Alcohol cue reactivity, negative-mood reactivity, and relapse in treated alcoholic men. J Abnorm Psychol 106:243-250.

George MS, Anton RF, Bloomer C, Teneback C, Drobes DJ, Lorberbaum JP, Nahas Z, Vincent DJ (2001) Activation of prefrontal cortex and anterior thalamus in alcoholic subjects on exposure to alcoholspecific cues. Arch Gen Psychiatry 58:345-352.

Gerrits MA, Wiegant VM, Van Ree JM (1999) Endogenous opioids implicated in the dynamics of experimental drug addiction: an in vivo autoradiographic analysis. Neuroscience 89:1219-1227.

Glautier S, Drummond DC (1994) Alcohol dependence and cue reactivity. J Stud Alcohol 55:224-229.

Katner SN, Magalong JG, Weiss F (1999) Reinstatement of alcoholseeking behavior by drug-associated discriminative stimuli after prolonged extinction in the rat. Neuropsychopharmacology 20:471-479.

Le AD, Quan B, Juzytch W, Fletcher PJ, Joharchi N, Shaham Y (1998) Reinstatement of alcohol-seeking by priming injections of alcohol and exposure to stress in rats. Psychopharmacology (Berl) 135:169-174.

Le AD, Poulos CX, Harding S, Watchus J, Juzytsch W, Shaham Y (1999) Effects of naltrexone and fluoxetine on alcohol self-administration and reinstatement of alcohol seeking induced by priming injections of alcohol and exposure to stress. Neuropsychopharmacology 21:435-444.

Le AD, Harding S, Juzytsch W, Watchus J, Shalev U, Shaham Y (2000) The role of corticotrophin-releasing factor in stress-induced relapse to alcohol-seeking behavior in rats. Psychopharmacology (Berl) 150:317-324.
Lindholm S, Ploj K, Franck J, Nylander I (2000) Repeated ethanol administration induces short- and long-term changes in enkephalin and dynorphin tissue concentrations in rat brain. Alcohol 22:165-171.

Macey DJ, Schulteis G, Heinrichs SC, Koob GF (1996) Time-dependent quantifiable withdrawal from ethanol in the rat: effect of method of dependence induction. Alcohol 13:163-170.

Martin-Fardon R, Ciccocioppo R, Massi M, Weiss F (2000) Nociceptin prevents stress-induced ethanol- but not cocaine-seeking behavior in rats. NeuroReport 11:1939-1943.

Meil WM, See RE (1996) Conditioned cued recovery of responding following prolonged withdrawal from self-administered cocaine in rats: an animal model of relapse. Behav Pharmacol 7:754-763.

Monti PM, Rohsenow DJ, Hutchison KE, Swift RM, Mueller TI, Colby SM, Brown RA, Gulliver SB, Gordon A, Abrams DB (1999) Naltrexone's effect on cue-elicited craving among alcoholics in treatment. Alcohol Clin Exp Res 23:1386-1394.

Nestby P, Vanderschuren LJ, De Vries TJ, Mulder AH, Wardeh G, Hogenboom F, Schoffelmeer AN (1999) Unrestricted free-choice ethanol self-administration in rats causes long-term neuroadaptations in the nucleus accumbens and caudate putamen. Psychopharmacology (Berl) 141:307-314.

O'Brien CP, Childress AR, Ehrman R, Robbins SJ (1998) Conditioning factors in drug abuse: can they explain compulsion? J Psychopharmacol 12:15-22.

Paxinos G, Watson C (1998) The rat brain in stereotaxic coordinates, Ed 4. San Diego: Academic.

Roberts AJ, Heyser CJ, Cole M, Griffin P, Koob GF (2000) Excessive ethanol drinking following a history of dependence: animal model of allostasis. Neuropsychopharmacology 22:581-594.

Rohsenow DJ, Monti PM, Hutchison KE, Swift RM, Colby SM, Kaplan GB (2000) Naltrexone's effects on reactivity to alcohol cues among alcoholic men. J Abnorm Psychol 109:738-742.

See RE, Grimm JW, Kruzich PJ, Rustay N (1999) The importance of a compound stimulus in conditioned drug-seeking behavior following one week of extinction from self-administered cocaine in rats. Drug Alcohol Depend 57:41-49.

Shaham Y, Erb S, Stewart J (2000) Stress-induced relapse to heroin and cocaine seeking in rats: a review. Brain Res Brain Res Rev 33:13-33.

Sinha R, Fuse T, Aubin LR, O'Malley SS (2000) Psychological stress, drug-related cues and cocaine craving. Psychopharmacology (Berl) 152:140-148.

Topple AN, Hunt GE, McGregor IS (1998) Possible neural substrates of beer-craving in rats. Neurosci Lett 252:99-102.

Weiss F, Lorang MT, Bloom FE, Koob GF (1993) Oral alcohol selfadministration stimulates dopamine release in the rat nucleus accumbens: genetic and motivational determinants. J Pharmacol Exp Ther 267:250-258.

Wilson AW, Costall B, Neill JC (2000) Manipulation of operant responding for an ethanol-paired conditioned stimulus in the rat by pharmacological alteration of the serotonergic system. J Psychopharmacol 14:340-346.

Zorrilla EP, Valdez GR, Weiss F (2001) Changes in levels of regional CRF-like-immunoreactivity and plasma corticosterone during protracted drug withdrawal in dependent rats. Psychopharmacology (Berl) 158:374-381. 